\title{
СОВРЕМЕННЫЕ ЭКСПЕРИМЕНТАЛЬНЫЕ МЕТОДЫ ПРЕДОТВРАЩЕНИЯ БАКТЕРИАЛЬНОЙ АДГЕЗИИ И НАРУШЕНИЯ ВНУТРЕННЕГО ГОМЕОСТАЗА БАКТЕРИЙ: ОБЗОР ЛИТЕРАТУРЫ
}

${ }^{1}$ Самохин А.Г., ${ }^{2}$ Козлова Ю.Н., ${ }^{3}$ Корнеев Д.В., ${ }^{3}$ Таранов О.С., ${ }^{1}$ Фёдоров Е.А., ${ }^{1}$ Павлов В.В., ${ }^{2}$ Морозова В.В., ${ }^{2}$ Сильников В.Н., ${ }^{2}$ Тикунова Н.В.

${ }^{\prime}$ ФГБУ «Новосибирский научно-исследовательский институт травматологии и ортопедии им. Я.Л. Цивьяна» Министерства здравоохранения Российской Федераиии, Новосибирск; e-mail: motorist@inbox.ru;

${ }^{2}$ ФГБУН «Институт химической биологии и фундаментальной медицины»» Сибирского отделения Российской академии наук (ИХБФМ СО РАН), Новосибирск; ${ }^{3}$ ФБУН «Государственный научный иентр вирусологии и биотехнологии "Вектор"» Федеральной службы по надзору в сфере защиты прав потребителей и благополучия человека (ФБУН ГНЦ ВБ «Вектор» Роспотребнадзора), Кольцово

\begin{abstract}
В настоящем обзоре рассмотрены два направления по предотвращению бактериальных инфекций: предотвращение адгезии к защищаемой поверхности, а также разрушение бактериальной клеточной стенки с нарушением/повреждением систем поддержания внутреннего гомеостаза бактерий. Показаны существующие проблемы в части защиты имплантатов путем нанесения на них разного рода покрытий, обладающих бактерицидным либо бактериостатическим действием, в качестве которых могут выступать катионы металлов, наночастицы, полиэлектролитных многослойных покрытий. Рассмотрены ограничения, связанные с возможностью использования ионов серебра в прикладных клинических применениях, наряду с освещением вопросов, касающихся их токсичности. Дано представление о различных ингибиторах эффлюксных насосов бактерий, экспериментальных работах по извращению метаболизма бактерий в рамках концепции «троянского коня» путем подмены ионов, участвующих в окислительно-восстановительных реакциях. Также представлены сведения об ингибиторах систем межмикробных взаимодействий (quorum sensing inhibitors) и о перспективности попыток создать антимикробные средства, выключающие указанные системы и/или нарушающие их работу.
\end{abstract}

Ключевые слова: бактерия, адгезия, покрытие, серебро, эффлюксный насос, бактериальный метаболизм, системы межбактериального взаимодействия

\section{MODERN EXPERIMENTAL METHODS OF BACTERIAL ADHESION PREVENTION AND BACTERIAL INTERNAL HOMEOSTASIS IMPAIRMENT: A REVIEW \\ ${ }^{1}$ Samokhin A.G., ${ }^{2}$ Kozlova Yu.N., ${ }^{3}$ Korneev D.V., ${ }^{3}$ Taranov O.S., ${ }^{1}$ Fedorov E.A., ${ }^{1}$ Pavlov V.V., ${ }^{2}$ Morozova V.V., ${ }^{2}$ Silnikov V.N., ${ }^{2}$ Tikunova N.V. \\ ${ }^{I}$ Novosibirsk research Institute of Traumatology and Orthopaedics n.a. Ya.L. Tsivyan, Novosibirsk; ${ }^{2}$ Institute of Chemical Biology and Fundamental Medicine, Siberian Branch of the Russian Academy of Sciences, Novosibirsk; ${ }^{3}$ Federal scientific centre of virology and biotechnology «Vector», Koltsovo}

In the present review two different classes of prevention of the bacterial infection were summarized, with aim to adhesion prevention to the target surface, destruction of the bacterial cell wall with mechanisms of impairment of the bacterial cell internal homeostasis. Current disadvantages in the implant protective coatings with bactericide or bacteriostatic action are reviewed (metal ions, nanoparticles, polyelectrolyte multilayered coatings), silver ions toxicity and limitations of its use in medicine was discussed. Paper also presented data on a different efflux pump inhibitors, experimental studies on induction of impairment in the bacterial metabolism («Trojan horse» concept), for example, replacement of an ions that plays crucial role in the redox reactions; quorum sensing inhibitors are reviewed with focus on the perspectives of antimicrobials on its basis.

Keywords: bacteria, adhesion, coating, silver, efflux pump, bacterial metabolism, quorum sensing inhibitors

Значимость проблемы нозокомиальных инфекций и инфицирования имплантируемых устройств и систем медицинского назначения в настоящее время бесспорна: проблема инфицирования области хирургического вмешательства и имплантатов медицинского назначения в клинической практике ежегодно приобретает всё большие масштабы, даже несмотря на примене- ние антибиотиков из групп гликопептидов и липопептидов. Ситуация такова, что из-за появления полирезистентных штаммов патогенных микроорганизмов по всему миру всё чаще приходится сталкиваться со штаммами бактерий, против которых или нет эффективного антибиотика или же для эффективного лечения пригоден лишь один класс антибиотиков [1]. Одной из причин этого 
является также и наличие бактериальных биопленок, существенно осложняющих проникновение многих антибиотиков к мишеням и значительно повышающих адаптационные возможности бактерий к новым условиям. Надо отметить, что бактериальной колонизации могут быть подвержены любые виды хирургических имплантатов, независимо от материала - будь то металлические либо полимерные, что заставляет, помимо доступных ныне в клинической практике методов, искать также и новые, в том числе неспецифические, способы воздействия на патогенные микроорганизмы.

Появление к настоящему времени все большего количества сведений о регуляции бактериальной адгезии, вирулентности и формировании биопленок, бактериальных межклеточных сигналов и механизмах энергетического обмена и биохимических реакций в клетках бактерий привело к расширению понимания дальнейшей стратегии и смещению акцентов в сторону превентивных мер, направленных в первую очередь на предупреждение колонизации имплантируемых устройств и систем патогенными микроорганизмами, нарушению формирования либо непосредственному повреждению биопленок с блокированием систем межмикробных взаимодействий и дестабилизации систем поддержания гомеостаза патогенной микробиоты [2].

Существующие на сегодняшний день экспериментальные исследовательские направления по предотвращению бактериальных инфекций можно условно классифицировать на следующие:

1. Предотвращение адгезии бактерий к защищаемой поверхности.

2. Разрушение бактериальной клеточной стенки и нарушение внутреннего гомеостаза бактерий; повреждение систем, отвечающих за поддержание гомеостаза.

3. Нарушение механизмов обмена бактериальными межклеточными сигналами.

4. Разрушение биофильма либо его компонентов.

5. Лизирование бактерий при помощи естественных биологических агентов.

В настоящем литературном обзоре будут рассмотрены первые два направления: предотвращение адгезии к защищаемой поверхности, а также разрушение бактериальной клеточной стенки с нарушением/повреждением систем поддержания внутреннего гомеостаза бактерий.

\section{Предотвращение адгезии бактерий к поверхностям}

Поскольку одной из ключевых экологических стратегий существования бактерий является их фиксация к твердым субстратам, наряду с образованием колоний, то на этапах филогенеза микроорганизмы сформировали развитый адаптивный механизм регуляции и реализации процесса адгезии к различным субстратам и поверхностям.

Бактерии обладают многочисленными комплексными механизмами адгезии, которые различаются у различных штаммов, и могут обладать быстрой изменчивостью в ходе мутаций в пределах даже одного штамма или под воздействием внешних стимулов, таких как достаточность ресурсов для питания либо скорость потока жидкости в среде [3].

Непосредственно адгезия регулируется путем экспрессии функциональных генов, отвечающих за формирование на поверхности бактериальной клетки необходимых для процесса адгезии макромолекулярных структур. Поверхность бактериальных клеток снабжена огромным количеством поверхностных связывающих молекул к различным белковым структурам внеклеточного матрикса макроорганизма-хозяина, таким как фибронектин, фибриноген, витронектин, эластин и ряду других, что позволяет рассматривать указанные матричные молекулы на поверхности клеток бактерий как единый комплекс, более известный как бактериальная система распознавания матричных молекул адгезии MSCRAMMs (microbial surface component recognizing adhesive matrix molecules), который играет одну из главенствующих ролей на этапе адгезии бактерии к поверхностям клеток макроорганизма [4]. Фактически, если упростить ситуацию до минимума, то различные варианты взаимодействия бактерий с внешней средой опосредованы химическими и физическими стимулами извне в ходе контактов с окружающими клетками и тканями, а также объектами неживой природы.

Дополнительными факторами, определяющими процесс адгезии микроорганизмов, являются поверхностный заряд клеточной мембраны, её гидрофобность, структура поверхностной мембраны и её экзополисахариды, а также возможное наличие жгутиков (пили) - последнее характерно для грамотрицательных микроорганизмов, хотя в определенных случаях преимущество, предоставляемое наличием жгутиков, варьирует в зависимости от штамма бактерий и условий роста колонии [5].

Необходимо также кратко упомянуть и то, что ряд используемых в медицинской отрасли материалов, в частности - некоторые металлы, совершенно не обладают антибактериальными свойствами в отношении наиболее распространенных грамполо- 
жительных и грамотрицательных микроорганизмов [6], что способствует быстрой колонизации имплантатов на их основе.

С учетом вышесказанного в настоящее время сформировались два основных направления борьбы с бактериальной адгезией к защищаемым поверхностям: обработка защищаемых поверхностей антибактериальными агентами различной природы либо воздействие непосредственно на сами процессы генной регуляции факторов адгезии бактерий.

В первом случае предложено значительное количество способов защиты: фиксация на поверхности защищаемого объекта агентов, обладающих бактерицидным либо бактериостатическим действием, в качестве которого могут выступать катионы металлов, в частности - ионы меди $[7,8]$, наночастицы серебра и покрытия на их основе $[9,10]$, формирование на поверхности защищаемых объектов полиэлектролитных многослойных покрытий, электрический заряд на поверхности которых препятствует адгезии [11], и даже многослойные покрытия из углеродных нанотрубок с заключенными в их слоях ферментами, в частности лизоцимом [12]. Тем не менее большая часть из этих методов пока еще не выходит за пределы исследовательских лабораторий, но даже по завершении всех необходимых испытаний предлагаемые методы могут занять лишь весьма узкую нишу в медицинской отрасли. В частности, применение различного рода покрытий в имплантируемых устройствах и системах сопряжено с их механическим соскабливанием непосредственно в процессе имплантации, например, в ортопедии, что может свести к минимуму эффективность такого подхода к профилактике колонизации имплантата. Более того, известны факты выработки устойчивости к самим антибактериальным агентам, в частности показано формирование устойчивости к серебру у ряда штаммов Pseudomonas aeruginosa и Acinetobacter baumannii [13], причем есть веские основания полагать, что эта устойчивость была опосредована за счет наличия соответствующих плазмидных генов (pUPI199), которую в эксперименте этих же авторов удалось успешно воспроизвести и у Escherichia coli после объединения с плазмидной ДНК. Учитывая то, что плазмидными генами может кодироваться как устойчивость к серебру, так и к антибиотикам, некоторые авторы рекомендуют использовать медицинские изделия с высоким содержанием ионов серебра для быстрого достижения желаемого эффекта [14], однако безвредность ионов серебра для собственных тканей макроорганизма в таком случае вызывает определенные сомнения. В частности, контакт с костной тканью серебра, иногда входящего в состав ряда ортопедических имплантатов, тормозит процессы остеогенеза [15] и способно вызывать остеолиз, что совершенно неприемлемо и может привести к серьезным последствиям. Показана также токсичность ионов серебра с крупным размером частиц - свыше 100 нм [16] и накопление частиц серебра в тканях мозга мышей, подвергнутых прямой инокуляции частиц серебра микронных размеров, с последующим образованием полостей в тканях и воспалительным процессом вокруг этих металлочастиц, сопровождающимся увеличением содержания провоспалительных цитокинов (в частности, фактор некроза опухоли-альфа) и связывающего металлические ионы металлотионеина, прогрессирующей утратой мозгового вещества (коры и гиппокампа) и увеличением боковых желудочков мозга [17].

Принципиально отличным способом от вышеописанного является воздействие на механизмы генной регуляции адгезии микроорганизмов. К настоящему моменту имеется достаточное количество свидетельств того, что создание нокаутных штаммов микроорганизмов и выработка антител к соответствующим регуляторным молекулам позволяет предотвратить процесс адгезии путем выключения передачи сигнального стимула, что открыло путь к созданию противоадгезивных вакцин [18]. Указанный подход позволил создать экспериментальные вакцины против фибриногенсвязывающего белка, фибронектинсвязывающего белка А и агглютинина А [19, 20].

В рамках этого направления можно выделить также следующие точки приложения для потенциальных противоадгезивных вакцин, действующих на механизмы биосборки адгезивных полимерных структур (пилей и ворсинок) - процесса, который на сегодняшний день уже достаточно хорошо охарактеризован и изучен [21]:

1. Ингибирование формирования шаперон-структурной субъединицы.

2. Торможение процесса полимеризации на этапе взаимодействий шаперон-структурной субъединицы с белком, отвечающим за её транслокацию из периплазмы через внешнюю мембрану.

3. Ингибирование при помощи антиадгезиновых антител прикрепления бактерий к рецепторам, расположенным на поверхности клеток хозяина.

Это стало возможным благодаря тому, что шапероны представляют собой высококонсервативную группу белков, играющих ключевую роль в процессах биогенеза 
адгезивных структур, что привело к созданию целой группы антибактериальных агентов - пилицидов, которые блокируют образование шаперон-структурной субъединицы путем специфичного и прочного связывания с шаперонами, препятствуя их взаимодействию с субъединицей. Некоторые пилициды обладают возможностью вызывать диссоциацию шаперон-структурной субъединицы, что гарантирует эффективное ингибирование образования адгезивных структур [21].

Тем не менее в том случае, если адгезия все-таки произошла, следующим рубежом вслед за средствами предотвращения адгезии следуют агенты, оказывающие непосредственное действие на сами микроорганизмы либо на формируемые ими биопленки, о чем пойдет речь далее.

\section{Разрушение бактериальной клеточной стенки и нарушение внутреннего гомеостаза бактерий}

Несмотря на наличие у бактерий достаточно эффективной защиты в виде биопленок, сама клеточная стенка и цитоплазма с её включениями достаточно уязвимы для внешних воздействий, что послужило основой для разработки и появления различных классов веществ, воздействующих на эти мишени.

Фактически общий принцип повреждающего воздействия на бактериальную клетку сводится к перфорации бактериальной стенки и последующему выравниванию осмотического давления между внутренней и внешней средой клетки, деструктивного для последней, либо к повреждению её метаболических процессов или цитоплазматических включений терапевтическим агентом, проникшим в клетку через её ионообменные транспортные механизмы. Поскольку настоящая статья не ставит своей целью рассмотрение механизмов действия различных классов антибиотиков, чему посвящено огромное множество литературных публикаций последних десятилетий, мы остановимся лишь на наиболее современных сведениях о разрабатываемых и перспективных методах непосредственного воздействия на клеточную стенку и цитоплазматические включения бактерий.

Одним из основных факторов противодействия бактерий в отношении различных классов антибиотиков является наличие у бактерий возможности удалять поступившие в них молекулы путем использования механизмов ионообменного трансмембранного транспорта. К настоящему моменту идентифицированы несколько разновидностей ионных эффлюксных на- сосов, способных удалять из клетки не только какой-либо конкретный антибиотик, но и одновременно несколько различных классов антибиотиков - эффлюксные насосы, обеспечивающие множественную лекарственную устойчивость бактерий к различным антибактериальным препаратам и способные к передаче подобной устойчивости через плазмидные гены [22, 23]. В качестве противодействия подобному защитному механизму были выделены и идентифицированы различные ингибиторы эффлюксных насосов (ИЭН), позволяющие нарушить работу ионообменного транспорта по удалению во внешнюю среду поступивших в клетку терапевтических агентов, что позволило эффективно снизить минимальные подавляющие концентрации для антибиотиков, необходимую для элиминации патогенных микроорганизмов. Так, указанный эффект показан при воздействии на кларитромицин-резистентные штаммы $E$. coli комбинацией из кларитромицина и ИЭН на основе фенил-аргинин-бета-нафтиламида [24], обработки Mycobacterium smegmatis при помощи фарнезола [23]. Достаточно большое количество ИЭН было обнаружено у растений, естественными патогенами для которых являются грамнегативные бактерии и грибы - так, некоторые растения рода барбариса (Berberis repens, $B$. aquifolia и $B$. fremontii) вырабатывают 5'-метоксигиднокарпин - ИЭН для NorA (эффлюксного насоса, обеспечивающего множественную лекарственную устойчивость) у Staphylococcus aureus [25]. Известно также, что растение Artemisia absinthium продуцирует кофеилхинную кислоту, являющуюся ИЭН для грамположительных патогенных бактерий [22].

Помимо ионообменного транспорта, клеточная стенка бактерий содержит еще целый ряд потенциальных мишеней для антибактериальной терапии, в частности - липиды клеточной стенки, которые весьма уязвимы для перекисного окисления, что ведет к её перфорации и последующему осмотическому разрушению бактерии. Непосредственным действием на липиды обладают вещества из группы порфиринов, которые способны реагировать как напрямую с биологическими структурами (реакции первого типа), так и путем катализа пероксидных и оксидазных реакций с последующим образованием активных форм кислорода. Их использование в фотодинамической терапии инфекционных процессов, вызванных грамположительными и грамотрицательными бактериями, достаточно хорошо описано в литературе, наряду со способностью металлопорфиринов увеличивать сенсиби- 
лизацию бактерий к свободным радикалам или же непосредственно вызывать их образование [26-28]. В свете вышесказанного об ИЭН существуют также экспериментальные данные, в которых были исследованы комбинации фотодинамической терапии с использованием верапамил гидрохлорида в качестве ИЭН по отношению к биопленке E. faecalis, сформированной на метиленовом синем, продемонстрировавшие эффективность такого подхода для разрушения биофильма, его структуры и находящихся в биофильме бактерий [29].

Одним из перспективных средств воздействия на патогенные микроорганизмы может стать необратимое повреждение нуклеиновых кислот, содержащихся в их ядерном аппарате, под воздействием искусственно синтезированных нуклеаз [30], поскольку идеальной мишенью для инактивации как вирусных, так и бактериальных патогенов является их геномная нуклеиновая кислота, разрушение которой любым методом приведет к потере патогеном способности к репликации и размножению. Результаты применения рибонуклеаз показывают, что они обеспечивают необратимое повреждение ДНК и РНК клеток в эксперименте [31], а также способны воздействовать на биопленку [32], что позволяет надеяться на их возможное применение в клинических условиях как универсального антисептического агента, действующего на вещества белковой природы. Тем не менее остаются нерешенными вопросы, касающиеся биологической безопасности рибонуклеаз для эукариотических клеток макроорганизма, что потребует дополнительного изучения.

Определенный интерес представляет собой возможность влияния на процессы захвата и метаболизма ионов трехвалентного железа, играющего важную роль в обеспечении ферментативных реакций бактерий. Последние обладают широкими возможностями по получению железа при нахождении в колонизированном организме хозяина, даже в условиях дефицита железа, характерного для живых систем, особенно в случае развития воспалительной реакции. Для этого у бактерий есть целый ряд механизмов, включающих использование как свободной формы железа путем её захвата специальными рецепторами на мембране клетки, так и возможность использования для этой цели поринов и сидерофоров [33-35]. В свете этого весьма интересным стал ряд публикаций, посвященных попытке реализации концепции «троянского коня» путем подмены ионов трехвалентного железа на комплексы трехвалентных галлия, индия и скандия, обладающие химическим сходством с трехвалентным железом, но не участвующие в окислительно-восстановительных реакциях бактериальных клеток, тем самым ингибируя их осуществление в клетке, захватившей эти ионы вместо ионов железа [2, 36, 37]. Есть ряд работ, посвященных ингибированию роста $P S$. aeruginosa наряду с биопленкой, формируемой этим микроорганизмом, в которых показаны различные пути доставки галлия в бактериальную клетку - использующие нитрит галлия $\mathrm{Ga}\left(\mathrm{NO}_{3}\right)_{3}$ [2] и соединение дезферриоксамина с галлием [38]. В последнем случае хоть и не был установлен механизм действия антибактериального агента, тем не менее желаемый эффект был достигнут - было отмечено подавление инфекционного процесса, вызванного Ps. aeruginosa при моделировании in vivo.

\section{Нарушение работы механизмов систем межмикробных взаимодействий}

Изучение механизмов сигнальных взаимодействий бактерий между собой является крайне важным для понимания процессов адгезии бактерий к субстрату, формирования колоний и регуляции её численности. За сигнальное обеспечение этих процессов у бактерий отвечают специфические секретируемые молекулы - автоиндукторы, а сам механизм называется «quorum sensing» или система межмикробных взаимодействий [39]. Данная система представляет собой способ межклеточных бактериальных коммуникаций, зависящий от плотности клеток на единицу объема, вовлеченный в экспрессию генов (в т.ч. генов вирулентности для экзоэнзимов, экзополисахаридов) и связанными с этим изменениями в поведении бактерий, находящихся в биопленке, включая их сопротивляемость к изменяющимся условиям внешней среды при большой плотности бактериальной колонии [39-41]. Основные известные на сегодня системы межмикробных взаимодействий описаны как система белковых рецепторов LuxR-LuxI у грамотрицательных бактерий, которая использует N-ацил-гомосеринлактон в качестве сигнальной молекулы и сигнальные системы agr/fsr, использующие PНКІІІ в качестве эффекторных молекул. Как в грамотрицательных, так и в грамположительных бактериях системы межмикробных взаимодействий регулируют экспрессию механизмов адгезии (биопленка и адгезины) и факторов вирулентности (токсины и экзоэнзимы) в зависимости от плотности колонии бактерий $[39,42]$. 
Разумеется, широта влияния этих систем на функциональную активность бактерий, в том числе способность к адгезии и формированию биопленок, привлекает значительный интерес с позиции поиска агентов, нарушающих работу этой системы - ингибиторов систем межмикробных взаимодействий, а также попытки создать антимикробные средства, выключающие указанные системы и нарушающие их работу.

Ряд идентифицированных к настоящему моменту таких ингибиторов представляют собой вещества, продуцируемые растениями в качестве неспецифического средства защиты против бактериальной колонизации, хотя есть и искусственно синтезированные вещества $[41,43]$, и даже выделенные непосредственно из числа продуцируемых самими бактериями - в частности, фенэтиламид и циклический дипептид [44]. Но KK et al. [43] в своей работе показали, что 5-метилен-1-(проп-2-эноил)4-фенил-дигидропиррол-2-1 способен предотвращать формирование биопленки Pseudomonas aeruginosa и Staphylococcus aureus при его использовании в качестве компонента искусственного защитного покрытия в модельном эксперименте.

Значительное количество экспериментальных работ было посвящено изучению веществ, блокирующих те или иные звенья систем межмикробных взаимодействий, что достаточно хорошо описано в обзорных литературных публикациях последних лет [4547] но несмотря на это ни один из ингибиторов систем межмикробных взаимодействий, опробованных на модельных животных, ещё пока непригоден для применения у человека [48], наряду с уже описанным в литературе возможным появлением устойчивости бактерий к некоторым таким ингибиторам либо появлением устойчивых штаммов бактерий, которые путем давления отбора могут заменить собой уязвимые к ингибиторам штаммы [49]. Тем не менее, это направление научного поиска (поиск и селекция ингибиторов систем межмикробных взаимодействий) является стабильно интересным с точки зрения возможных перспективных методов предотвращения развития инфекционного процесса у человека, поскольку подобные агенты являются весьма многообещающей альтернативой антибиотикам либо средством для потенцирования их эффекта за счет синергетического действия антибиотика и ингибитора.

\section{Заключение}

Настоящий краткий обзор литературы освещает лишь часть из широкого арсена- ла перспективных средств воздействия на патогенные бактерии и их колонии, а также демонстрирует необходимость постоянного дальнейшего поиска механизмов контроля бактериальной колонизации имплантируемых устройств и систем медицинского назначения, поскольку бактериальные инфекции представляют собой одну из серьезнейших проблем в современной медицине и медицине будущего, в связи с чем усилия исследователей должны концентрироваться на целом ряде направлений, максимально полно охватывающих широкий диапазон уязвимостей бактерий и их колоний.

\section{Список литературы}

1. Skurnik D., Davis M., Benedetti D. et al. Targeting PanResistant Bacteria With Antibodies to a Broadly Conserved Surface Polysaccharide Expressed During Infection. The Journal of Infectious Diseases, 2012, 205(11), 1709-1718.

2. Kaneko Y., Thoendel M., Olakanmi O., Britigan B.E., Singh P.K. The transition metal gallium disrupts Pseudomonas aeruginosa iron metabolism and has antimicrobial and antibiofilm activity. J Clin Invest, Apr 2007, Vol. 117(4), P. 877-888.

3. Il'ina T.S., Romanova Iu.M., Gintsburg A.L. [Biofilms as a mode of existence of bacteria in external environment and host body: the phenomenon, genetic control, and regulation systems of development]. [Article in Russian] Genetika, 2004 Nov, $40(11), 1445-56$.

4. Patti J.M., Allen B.L., McGavin M.J., Hook M. MSCRAMM-mediated adherence of microorganisms to host tissues. Annu. Rev. Microbiol, 1994, 48, 585-617.

5. Clegg S, Wilson J, Johnson J. More than one way to control hair growth: Regulatory mechanisms in enterobacteria that affect fimbriae assembled by the chaperone/usher pathway. J Bacteriol. 2011 May, 193(9), 2081-8.

6. Yasuyuki M., Kunihiro K., Kurissery S., Kanavillil N., Sato Y., Kikuchi Y. Antibacterial properties of nine pure metals: a laboratory study using Staphylococcus aureus and Escherichia coli. Biofouling, 2010 Oct, 26(7), 851-8.

7. Grass G., Rensing C., Solioz M. Metallic copper as an antimicrobial surface. Appl Environ Microbiol, 2011 Mar, 77(5), 1541-7.

8. Quaranta D., Krans T., Espírito Santo C., Elowsky C.G., Domaille D.W., Chang C.J., Grass G. Mechanisms of contactmediated killing of yeast cells on dry metallic copper surfaces. Appl Environ Microbiol, 2011 Jan, 77(2), 416-26.

9. Jung W.K., Koo H.C., Kim K.W., Shin S., Kim S.H., Park Y.H. Antibacterial Activity and Mechanism of Action of the Silver Ion in Staphylococcus aureus and Escherichia coli Applied and Environmental Microbiology, April 2008, p. 21712178, Vol. 74, No. 7.

10. Edwards-Jones V. Antimicrobial and barrier effects of silver against methicillin-resistant Staphylococcus aureus Journal of Wound Care, Vol. 15, Iss. 7, 01 Jul 2006, P. 285-290.

11. Lichter J.A., Van Vliet K.J., Rubner M.F. Design of Antibacterial Surfaces and Interfaces: Polyelectrolyte Multilayers as a Multifunctional Platform. Macromolecules, 2009, 42 (22), P. 8573-8586.

12. Nepal D., Balasubramanian S., Simonian A.L., Davis V.A. Strong Antimicrobial Coatings: Single-Walled Carbon Nanotubes Armored with Biopolymers Nano Lett., 2008, 8 (7), P. $1896-1901$

13. Deshpande LM and Chopade BA. Plasmid mediated silver resistance in Acinetobacter baumannii. Biometals, 1994, 7, 49-56.

14. Chopra I. The increasing use of silver-based products as antimicrobial agents: a useful development or a cause for 
concern? Journal of Antimicrobial Chemotherapy, 2007, 59(4), $587-590$.

15. Ahrens H., Dieckmann R., Streitbürger A., Balke M., Gosheger G., Günsel A., Hardes. J. Where is the limit of silvercoatings as toxic agent against early and late infections in megaendoprosthesis? Journal of Bone and Joint Surgery, British Volume, 2010, Vol 92-B, Issue Supp III, p. 464-465.

16. Gorth D.J., Rand D.M., Webster T.J. Silver nanoparticle toxicity in Drosophila: size does matter. Int J Nanomedicine, 2011, 6, 343-50.

17. Locht L.J., Pedersen M.O., Markholt S., Bibby B.M., Larsen A., Penkowa M., Stoltenberg M., Rungby J. Metallic Silver Fragments Cause Massive Tissue Loss in the Mouse Brain. Basic Clin Pharmacol Toxicol, 2011 Jul,109(1), 1-10.

18. Arciola C.R. New concepts and new weapons in implant infections. Int J Artif Organs, 2009 Sep, 32(9), 533-6.

19. Scarpa M, Piccinini R, Brun P, Grillo A, Palù G, Mengoli $\mathrm{C}$, Daprà $\mathrm{V}$, Castagliuolo I, Zecconi $\mathrm{A}$. Relationship between virulence factor genes in bovine Staphylococcus aureus subclinical mastitis isolates and binding to anti-adhesin antibodies. J Dairy Res, 2010 May, 77(2), 159-67.

20. Gong R., Hu C., Xu H., Guo A., Chen H., Zhang G., Shi L. Evaluation of clumping factor A binding region $\mathrm{A}$ in a subunit vaccine against Staphylococcus aureus-induced mastitis in mice. Clin Vaccine Immunol, 2010 Nov, 17(11), 1746-52.

21. Piątek R., Zalewska B., Bury K., Kur J. The chaperoneusher pathway of bacterial adhesin biogenesis - from molecular mechanism to strategies of anti-bacterial prevention and modern vaccine design. Acta Biochimica Polonica, Vol. 52, No. 3/2005, 639-646.

22. Fiamegos Y.C., Kastritis P.L., Exarchou V., Han H., Bonvin A.M., Vervoort J., Lewis K., Hamblin M.R., Tegos G.P. Antimicrobial and Efflux Pump Inhibitory Activity of Caffeoylquinic Acids from Artemisia absinthium against GramPositive Pathogenic Bacteria, PLoS One, 2011 Apr 4, 6(4), e18127.

23. Jin J., Zhang J.Y., Guo N., Sheng H., Li L., Liang J.C., Wang X.L., Li Y., Liu M.Y., Wu X.P., Yu L. Farnesol, a potential efflux pump inhibitor in Mycobacterium smegmatis. Molecules, 2010 Oct $29,15(11), 7750-62$.

24. Hirata K., Suzuki H., Nishizawa T., Tsugawa H., Muraoka H., Saito Y., Matsuzaki J., Hibi T. Contribution of efflux pumps to clarithromycin resistance in Helicobacter pylori. J Gastroenterol Hepatol, 2010 May, 25, Suppl 1, S75-9.

25. Stermitz F.R., Lorenz P., Tawara J.N., Zenewicz L.A., Lewis K. Synergy in a medicinal plant: antimicrobial action of berberine potentiated by 5'-methoxyhydnocarpin, a multidrug pump inhibitor. Proc Natl Acad Sci U S A, 2000 Feb 15, 97(4), $1433-7$.

26. Alves E., Costa L., Carvalho C.M., Tomé J.P., Faustino M.A., Neves M.G., Tomé A.C., Cavaleiro J.A., Cunha A., Almeida A. Charge effect on the photoinactivation of Gramnegative and Gram-positive bacteria by cationic meso-substituted porphyrins. BMC Microbiol, 2009 Apr 15, 9, 70.

27. Stojiljkovic I., Evavold B.D., Kumar V. Antimicrobial properties of porphyrins. Expert Opin Investig Drugs, $2001 \mathrm{Feb}$, 10(2), 309-20.

28. Afonso S.G., Enríquez de Salamanca R, Batlle AM. The photodynamic and non-photodynamic actions of porphyrins. Braz J Med Biol Res, 1999 Mar, 32(3), 255-66.

29. Kishen A., Upadya M., Tegos G.P., Hamblin M.R. Efflux pump inhibitor potentiates antimicrobial photodynamic inactivation of Enterococcus faecalis biofilm. Photochem Photobiol, 2010 Nov-Dec, 86(6), 1343-9.

30. Koroleva L.S., Silnikov V.N. Toward the development of metal-free synthetic nucleases cleavage of a model substrates by bis-quaternary salts of 1,4-diazabicyclo[2.2.2]octane derivatives. Nucleosides Nucleotides Nucleic Acids, 2004, Vol. 23, P. 993-996.

31. Yang Q., Xu J., Sun Y., Li Z., Li Y., Qian X. Hydrolysis of plasmid DNA and RNA by amino alkyl naphthalimide as metal-free artificial nuclease Bioorganic \& Medicinal Chemistry Letters, 15 February 2006, Volume 16, Issue 4, P. 803-806.

32. Hall-Stoodley L., Nistico L., Sambanthamoorthy K., Dice B., Nguyen D., Mershon W.J., Johnson C., Hu F.Z., Stoodley P., Ehrlich G.D., Post J.C. Characterization of biofilm matrix, degradation by DNase treatment and evidence of capsule downregulation in Streptococcus pneumoniae clinical isolates, BMC Microbiol, 2008, 8, 173.

33. Chu B.C., Garcia-Herrero A., Johanson T.H., Krewulak K.D., Lau C.K., Peacock R.S., Slavinskaya Z., Vogel H.J. Siderophore uptake in bacteria and the battle for iron with the host; a bird's eye view. Biometals, 2010 Aug, 23(4), 601-11.

34. Jones C.M., Niederweis M. Role of porins in iron uptake by Mycobacterium smegmatis. J Bacteriol, 2010 Dec, 192(24), 6411-7.

35. Clarke T.E., Tari L.W., Vogel H.J. Structural biology of bacterial iron uptake systems. Curr Top Med Chem, 2001 May, 1(1), 7-30.

36. Rogers H.J., Woods V.E., Synge C. Antibacterial effect of the scandium and indium complexes of enterochelin on Escherichia coli. J Gen Microbiol, 1982 Oct, 128(10), 2389-94.

37. Stojiljkovic I., Kumar V., Srinivasan N. Non-iron metalloporphyrins: potent antibacterial compounds that exploit haem/Hb uptake systems of pathogenic bacteria. Mol Microbiol, 1999 Jan, 31(2), 429-42.

38. Banin E., Lozinski A., Brady K.M., Berenshtein E., Butterfield P.W., Moshe M., Chevion M., Greenberg E.P. The potential of desferrioxamine-gallium as an anti-Pseudomonas therapeutic agent. Proc Natl Acad Sci USA, 2008 October 28, 105(43), 16761-16766.

39. Costerton J.W., Montanaro L., Arciola C.R. Bacterial communications in implant infections: a target for an intelligence war. Int J Artif Organs, 2007 Sep, 30(9), 757-63.

40. Lazar V. Quorum sensing in biofilms - How to destroy the bacterial citadels or their cohesion/power? Anaerobe, 2011 Dec, 17(6), 280-5.

41. Palmer A.G., Streng E., Jewell K.A., Blackwell H.E. Quorum sensing in bacterial species that use degenerate autoinducers can be tuned by using structurally identical non-native ligands. Chembiochem, 2011 Jan 3, 12(1), 138-47.

42. Shojima A., Nakayama J. Quorum sensing in grampositive bacteria: assay protocols for staphylococcal agr and enterococcal fsr systems. Methods Mol Biol, 2014, 1147:33-41.

43. Ho K.K., Cole N., Chen R., Willcox M.D., Rice S.A., Kumar N. Characterisation and in vitro activities of surface attached dihydropyrrol-2-ones against Gram-negative and Grampositive bacteria. Biofouling, $2010 \mathrm{Nov}, 26(8), 913-21$.

44. Teasdale M.E., Donovan K.A., Forschner-Dancause S.R., Rowley D.C. Gram-Positive Marine Bacteria as a Potential Resource for the Discovery of Quorum Sensing Inhibitors. Mar Biotechnol (NY), 2011 Aug, 13(4), 722-32.

45. Boyer M., Wisniewski-Dyé F. Cell-cell signalling in bacteria: not simply a matter of quorum. FEMS Microbiol Ecol, 2009 Oct, 70(1), 1-19.

46. Raffa R.B., Iannuzzo J.R., Levine D.R., Saeid K.K., Schwartz R.C., Sucic N.T., Terleckyj O.D., Young J.M. Bacterial communication («quorum sensing») via ligands and receptors: a novel pharmacologic target for the design of antibiotic drugs. J Pharmacol Exp Ther, 2005 Feb, 312(2), 417-23.

47. Otto M. Quorum-sensing control in Staphylococci -a target for antimicrobial drug therapy? FEMS Microbiol Lett, 2004 Dec 15, 241(2), 135-41.

48. Kunze B., Reck M., Dötsch A., Lemme A., Schummer D., Irschik H., Steinmetz H., Wagner-Döbler I. Damage of Streptococcus mutans biofilms by carolacton, a secondary metabolite from the myxobacterium Sorangium cellulosum. BMC Microbiol, 2010, 10, 199.

49. Kalia V.C., Wood T.K., Kumar P. Evolution of resistance to quorum-sensing inhibitors. Microb Ecol, 2014 Jul, 68(1), $13-23$. 